\title{
Family Medicine Outpatient Encounters are More Complex Than Those of Cardiology and Psychiatry
}

\author{
David Katerndahl, MA, MD, Robert Wood, DrPH, and Carlos Roberto Jaén, MD, PhD
}

Background: Comparison studies suggest that the guideline-concordant care provided for specific medical conditions is less optimal in primary care compared with cardiology and psychiatry settings. The purpose of this study is to estimate the relative complexity of patient encounters in general/family practice, cardiology, and psychiatry settings.

Methods: Secondary analysis of the 2000 National Ambulatory Medical Care Survey data for ambulatory patients seen in general/family practice, cardiology, and psychiatry settings was performed. The complexity for each variable was estimated as the quantity weighted by variability and diversity.

Results: There is minimal difference in the unadjusted input and total encounter complexity of general/family practice and cardiology; psychiatry's input is less complex. Cardiology encounters involved more input quantitatively, but the diversity of general/family practice input eliminated the difference. Cardiology also involved more complex output. However, when the duration of visit is factored in, the complexity of care provided per hour in general/family practice is $33 \%$ more relative to cardiology and 5 times more relative to psychiatry.

Conclusions: Care during family physician visits is more complex per hour than the care during visits to cardiologists or psychiatrists. This may account for a lower rate of completion of process items measured for quality of care. (J Am Board Fam Med 2011;24:6-15.)

Keywords: Family Practice, Nonlinear Dynamics, Quality of Care, Specialization, Systems Theory

Although ecological studies consistently find that the supply of primary care physicians is associated with better quality of care, better population health, and lower cost of care, ${ }^{1}$ there is a sizable body of literature suggesting that, compared with generalists, specialists are more likely to provide effective disease-specific care, but at a cost of increased resource use and hospital stays. ${ }^{2}$ Comparison studies suggest that the process quality of care provided for specific medical conditions is poorer in primary care than in specialty settings.

This article was externally peer reviewed.

Submitted 12 March 2010; revised 18 August 2010; accepted 27 August 2010.

From the Departments of Family and Community Medicine (DK, RW, CRJ) and Epidemiology and Biostatistics (CRJ), University of Texas Health Science Center at San Antonio, San Antonio.

Funding: This project was supported in part by a grant from the Texas Academy of Family Physicians Foundation (DK).

Conflict of interest: none declared.

Corresponding author: David Katerndahl, MD, Department of Family and Community Medicine, University of Texas Health Science Center, 7703 Floyd Curl Drive, San Antonio, TX 78229-3900 (E-mail: katerndahl@uthscsa.edu).
Specifically, when comparing generalists with cardiologists, family physicians more often recommend therapies, which are less beneficial for acute myocardial infarction, than do cardiologists, ${ }^{3,4}$ with an inconsistent finding of higher mortality. ${ }^{5,6} \mathrm{Sim}$ ilarly, patients with unstable angina are less likely to receive effective treatments if treated by generalists rather than cardiologists. ${ }^{7,8}$ In addition, compared with generalists, cardiologists are less likely to order tests but prescribe more medications for hypertension and ischemic heart disease. ${ }^{9}$ Cardiologists also perform more cardiac catheterizations, ${ }^{10}$ more echocardiograms, and prescribe more evidencebased medications for patients with heart failure. ${ }^{11,12}$ Consequently, patients hospitalized for heart failure had higher short-term ${ }^{13}$ and longterm ${ }^{14}$ mortality rates if cared for by generalists. However, because the patients seen by family physicians often differed significantly from those seen by cardiologists in many demographic and clinical features, it is difficult to know whether statistical adjustment in these observational studies was adequate to control for such differences. 
Similar differences between primary care physicians' and psychiatrists' treatment of patients with mental disorders have been reported. Studies suggest that, compared with psychiatrists, primary care physicians more often fail to detect mental disorders, ${ }^{15-17}$ make more diagnostic errors, ${ }^{18,19}$ and more often use inappropriate or inadequate dosages of psychotropic medications. ${ }^{20,21}$ However, not every study comparing psychiatrists and primary care physicians have found significant treatment differences. $^{22}$ Outcome-based quality of care studies can be misleading. ${ }^{23}$ In fact, in a systematic review of the generalist-specialist quality of care literature, studies favoring specialist care were less likely to control for 4 key potential confounders: (1) physician volume or experience, (2) information technology support, (3) care management programs, and (4) practice size and integration into delivery systems. ${ }^{24}$

If we accept that these generalist-specialist differences are real, what is the explanation? Because those entering primary care residencies have similar scores on standardized examinations as those entering other residencies, ${ }^{25}$ differences in quality of care provided must have a cause other than differences in intelligence. Most comparison studies are observational and focus on process rather than outcome, and specialists have longer office visits with more time available to perform process measures whereas primary care physicians must prioritize the use of time during encounters. However, primary care physicians may provide poorer process-based, disease-specific quality of care as a consequence of the complexity of the encounter and environment in primary care as opposed to the narrow focus of the specialty setting.

The complexity of health care in the United States has increased dramatically. Not only has there been an explosion in medical knowledge, but the system itself has also grown more complex in terms of its payers, ${ }^{26}$ guidelines, ${ }^{27}$ and medications. ${ }^{28}$ One potential consequence of increasing complexity is the provision of poorer quality of care. ${ }^{28}$ The purpose of this study was to build on previous work, estimating the relative complexity of patient encounters in general/family practice, cardiology, and psychiatry settings using data from the 2000 National Ambulatory Medical Care Survey (NAMCS), dissecting the sources of complexity within practice. ${ }^{26} \mathrm{We}$ hypothesized that estimates of complexity, particularly the complexity of the input, will be higher in general/family practice than in either cardiology or psychiatry, primarily because of differences in diversity across visits. Differences should be magnified when adjusted for differences in the duration of office visit. Cardiologists and psychiatrists were chosen as comparison groups because a large portion of the generalistspecialist comparison literature involves these specialties.

\section{Methods \\ Sample}

The 2000 NAMCS database was used in this secondary analysis. ${ }^{29}$ NAMCS used a multistage probability design of primary sampling units throughout the United States, practices within primary sampling units, and patient visits within practices. Trained physicians and office staff completed encounter data on patient visits selected. This data included patients' symptoms, physicians' diagnoses, diagnostic procedures, and treatments provided. Only data provided by general/family practitioners $(\mathrm{n}=3344)$, cardiovascular specialists $(\mathrm{n}=1650)$, and psychiatrists $(n=1567)$ were retained for this analysis.

\section{Data}

Patient encounters can be described by the quantity of information and services exchanged between patient and physician, by the visit-to-visit variability of these exchanges, and by their overall diversity. ${ }^{30}$ "Quantification" of patient visits included the per patient number of reasons for visit, diagnoses, body systems examined and tests ordered, medications prescribed, procedures performed, and other therapies ordered. In addition, whether patients were new to the practice was also recorded.

"Variability" was measured across visits within disciplines by computing the coefficient of variation $(\mathrm{COV})$ from the mean and standard deviation from quantities measured above. In addition, the $\mathrm{COV}$ of the age of patients seen was also computed.

"Diversity" was defined as the proportion of categories needed to describe $95 \%$ of the visits for each discipline. For each variable, the entire database was used to determine how many categories were needed to describe $95 \%$ of the visits (possible categories). This procedure was then repeated for each discipline, and diversity was computed as the proportion of possible categories that were needed 
to describe $95 \%$ of visits within that discipline. Finally, patient demographic diversity was assessed as the proportion of categories within a sex $\mathrm{X}$ race $\mathrm{X}$ ethnicity matrix needed to describe $95 \%$ of patients seen.

The 2000 NAMCS data set provides a patient weight that allows the sample of 27,369 visits to be "inflated" to represent the total of $832,541,999$ visits that year in the United States. This patient visit weight was applied to the dataset so that estimates of complexity parameters produced by resampling techniques would better conform to national patterns of patient encounters. ${ }^{29}$

\section{Analysis}

Visit input depended on the reasons for the visit, diagnoses, examination/testing, and patient characteristics. Visit output depended on medications and therapies prescribed, procedures performed, and disposition. In addition to the mean quantification for each variable, differences in the discipline-specific duration of visit were used for time-dependent variables (reasons for visit, diagnoses examination/ testing, medications, procedures, and other therapies) to determine an hourly complexity rate for each discipline.

"Complexity" was calculated from the data extracted above using a previously described procedure (see Figure 1). ${ }^{30}$ The complexity of continuous measures was calculated as the mean value for each variable weighted for variability and diversity.
These weights were computed as the Z-transformations of the COVs and diversity proportions. The complexity of patient demographic characteristics could not be computed in this manner, and was thus defined as the diversity of each of the 3 patient characteristic measures and estimated as the sum of the Z-transformations of the proportion of new patients, the variability of patients' ages, and the demographic diversity. This method would yield a complexity estimate with a possible range comparable to the ranges of the other input variables. The complexity of the encounters is calculated by the following formula ${ }^{31}$ :

complexity $($ total $)=$ complexity (output) $\times 2^{\text {complexity (input) }}$

Thus, total complexity is more dependent on the complexity of the input than that of the output. Because complexity parameters are not computed using the individual practitioner as a unit of measurement, there were no corresponding measures of parameter variation. Bootstrap procedures were used to provide estimates of error for selected measures of complexity. The standard errors have been provided to enable the computation of $95 \%$ CIs (mean $\pm 2 \mathrm{SE}=95 \% \mathrm{CI}$ ). Because of the large sample size, most of the interspecialty comparisons are statistically significant.

Figure 1. Computation of Relative Complexity of Ambulatory Care

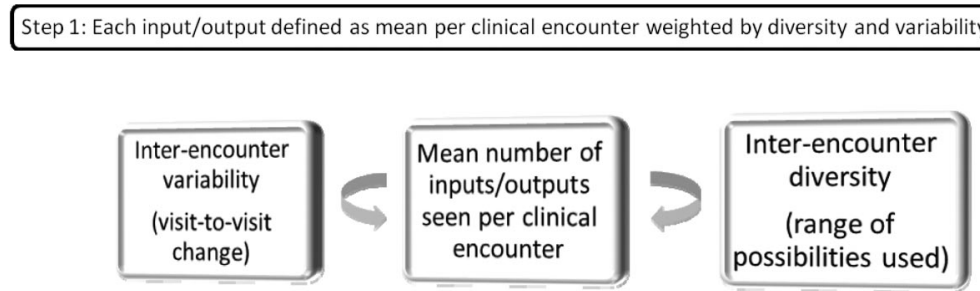

Step 2: Total Input and Total Output complexities calculated by summing components complexities

Step 3: Total Complexity is the product of output complexity and 2 raised to the power of input complexity

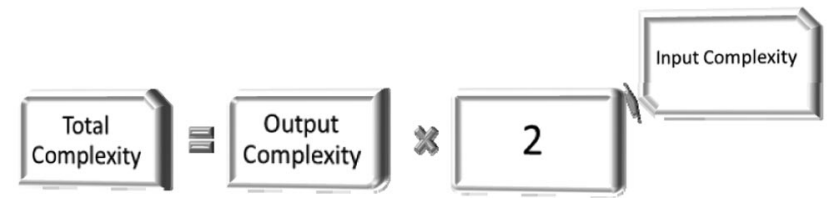


Table 1. Quantification of Ambulatory Care Provided across Disciplines

\begin{tabular}{|c|c|c|c|}
\hline Variable & $\begin{array}{l}\text { General/Family Practice } \\
\qquad(\mathrm{n}=3344)\end{array}$ & $\begin{array}{l}\text { Cardiology } \\
(\mathrm{n}=1650)\end{array}$ & $\begin{array}{l}\text { Psychiatry } \\
(\mathrm{n}=1567)\end{array}$ \\
\hline \multicolumn{4}{|l|}{ Input (mean per visit) } \\
\hline Reasons for visit & $1.61(0.00001)$ & $1.44(0.00001)$ & $1.57(0.00001)$ \\
\hline Diagnoses & $1.70(0.00001)$ & $1.97(0.00001)$ & $1.39(0.00001)$ \\
\hline Examination/testing & $1.68(0.00002)$ & $1.97(0.00002)$ & $0.14(0.00001)$ \\
\hline \multicolumn{4}{|l|}{ Patient characteristics } \\
\hline Proportion of new patients & $0.08(0.000003)$ & $0.13(0.000006)$ & $0.11(0.000005)$ \\
\hline \multicolumn{4}{|l|}{ Output (mean per visit) } \\
\hline Medications prescribed & $1.80(0.00002)$ & $2.94(0.00004)$ & $1.60(0.00002)$ \\
\hline Procedures & $0.03(0.00000)$ & $0.01(0.00000)$ & 0 \\
\hline Other therapies & $0.61(0.00001)$ & $0.59(0.00001)$ & $1.52(0.00002)$ \\
\hline
\end{tabular}

Values provided as weighted mean (SE).

$\mathrm{n}$, number of visits.

\section{Results}

\section{Encounters}

Table 1 presents the quantitative description of the patient encounters in general/family practice, cardiology, and psychiatry. Although the numbers of reasons for visits were similar across the disciplines, cardiology patient encounters had more diagnoses and received more examination and testing; psychiatry encounters involved the fewest and used the most other therapies. However, when controlling for differences in duration of visit, general/family practice encounters included the highest complexity rates of reasons for visit, diagnoses, and examination/testing. Outputs varied considerably across disciplines: cardiology visits involved the most medications, general/ family practice visits involved the most procedures, and psychiatry visits involved the most other therapies. Adjustment for duration of visit affected the psychiatry measures most.
Table 2 presents the variability in encounters across disciplines. Although variability in the number of reasons for visit and diagnoses were similar, psychiatry visits were the most variable in examination and testing. Although the variability in medications prescribed was similar across disciplines, cardiology visits were the most variable in procedures whereas psychiatry visits were least variable in other therapies used.

Table 3 presents descriptors of diversity across disciplines. As expected, general/family practice visits involved the most diversity in reasons for visit, diagnoses, and most outputs. Demographic diversity, however, was almost identical across specialties.

\section{Complexity}

Table 4 summarizes the complexity across disciplines. The differences in input complexity are

Table 2. Variability of Ambulatory Care Provided across Disciplines

\begin{tabular}{|c|c|c|c|}
\hline Variable & $\begin{array}{c}\text { General/Family Practice } \\
(\mathrm{n}=3344)\end{array}$ & $\begin{array}{l}\text { Cardiology } \\
(\mathrm{n}=1650)\end{array}$ & $\begin{array}{l}\text { Psychiatry } \\
(\mathrm{n}=1567)\end{array}$ \\
\hline \multicolumn{4}{|l|}{ Input } \\
\hline Reasons for visit & $0.49(0.00000)$ & $0.52(0.00000)$ & $0.52(0.00000)$ \\
\hline Diagnoses & $0.50(0.00000)$ & $0.45(0.00001)$ & $0.50(0.00000)$ \\
\hline Examination/testing & $1.01(0.00001)$ & $0.76(0.00001)$ & $3.05(0.00007)$ \\
\hline Patient characteristics (age) & $0.53(0.00000)$ & $0.22(0.00000)$ & $0.44(0.00001)$ \\
\hline \multicolumn{4}{|l|}{ Output } \\
\hline Medications prescribed & $0.94(0.00001)$ & $0.78(0.00001)$ & $0.81(0.00001)$ \\
\hline Procedures & $6.35(0.0002)$ & $14.67(0.0018)$ & - \\
\hline Other therapies & $1.68(0.00002)$ & $1.56(0.00003)$ & $0.70(0.00001)$ \\
\hline
\end{tabular}

Values provided as weighted coefficient of variation (SE).

$\mathrm{n}$, number of visits. 
Table 3. Diversity of Ambulatory Care Provided across Disciplines

\begin{tabular}{|c|c|c|c|c|}
\hline Variable & $\begin{array}{c}\text { Possible } \\
\text { Categories (n) }\end{array}$ & $\begin{array}{l}\text { General/Family Practice* } \\
\qquad(\mathrm{n}=3344)\end{array}$ & $\begin{array}{l}\text { Cardiology* } \\
(\mathrm{n}=1650)\end{array}$ & $\begin{array}{l}\text { Psychiatry* } \\
(\mathrm{n}=1567)\end{array}$ \\
\hline \multicolumn{5}{|l|}{ Input } \\
\hline Reasons for visit & 355 & $0.50(0.00002)$ & $0.24(0.00001)$ & $0.11(0.00002)$ \\
\hline Diagnoses & 491 & $0.47(0.00003)$ & $0.19(0.00003)$ & $0.06(0.00001)$ \\
\hline Examination/testing & 96 & $0.22(0.00006)$ & $0.21(0.00008)$ & $0.28(0.0009)$ \\
\hline \multicolumn{5}{|l|}{ Patient characteristics } \\
\hline Demographic diversity $^{\dagger}$ & 16 & $0.62(0.00042)$ & $0.63(0.00000)$ & $0.62(0.00048)$ \\
\hline \multicolumn{5}{|l|}{ Output } \\
\hline Medications prescribed & 113 & $0.50(0.00002)$ & $0.33(0.0001)$ & $0.09(0.00005)$ \\
\hline Procedures & 37 & $0.65(0.00014)$ & $0.16(0.00008)$ & - \\
\hline Other therapies & 46 & $0.37(0.00047)$ & $0.20(0.00098)$ & $0.23(0.00038)$ \\
\hline Disposition & 5 & $0.60(0.00000)$ & $0.60(0.00000)$ & $0.40(0.00000)$ \\
\hline
\end{tabular}

Values provided as weighted proportion (SE).

*Proportion of possible categories needed to include $95 \%$ of patients; $n$, number of visits.

${ }^{\dagger}$ Proportion of categories (sex $\times$ race $\times$ ethnicity).

small but generally largest in general/family practice with the exception that cardiology visits have the most complex examination and testing. When adjusted for the duration of visit, these differences were magnified. In several cases, the relative ranking of encounter complexity changed when adjusted for the duration of visit. For example, the unadjusted complexity of outputs was largest in cardiology because of the complexity of medications prescribed. When adjusting for duration of visit, the medication complexity for cardiology dropped and general/family practice outputs were now the most complex. Because the complexity of the input drove the total encounter complexity, general/family practice was most complex. This difference was magnified when adjusted for duration of visit; as reported previously, ${ }^{26}$ the adjusted complexity for general/family practice is $33 \%$ more than that of cardiology and 5 times that of psychiatry.

\section{Discussion}

Complex adaptive systems balance complicated interactions with adaptability, often demonstrating a combination of both linear predictability and nonlinear unpredictability. ${ }^{32}$ Adaptive processes often have a stable linear framework to which an adaptive nonlinear pattern is added. ${ }^{33}$ In the case of patient encounters, the "complicatedness" of input complexity may increase the demands placed on the provider, but the adaptability of output complexity allows the provider to tailor management to the patient and context.

\section{Encounter Complexity}

Because primary care patients present earlier in the course of their illness and with less differentiated disease, ${ }^{34}$ we would expect that the input in family medicine would be less clear and, hence, more complex. This agrees with the conclusions of the Future of Family Medicine Project. ${ }^{35}$ In addition, primary care physicians, potentially filtering out those with uncertain diagnoses, have already evaluated patients who were referred to specialists. Recognition that the probability of disease is lower in primary care may explain higher rates of testing in specialty practice. ${ }^{36}$ Thus, the complexity observed in family medicine versus cardiology is understandable based on the patients who present and the referral process. What characterizes family medicine the most is the diversity that defines it. ${ }^{37}$

Output complexity was highest in cardiology practices because of medication complexity. Further complicating the picture is the significant intraphysician variability observed among general practitioners. ${ }^{38}$ Such findings suggest that encounters in family medicine may be even more complex than we can assess here.

Because total encounter complexity is more dependent on complexity of the input than the output, the complexity of family medicine is greater than that of cardiology and psychiatry. This reflects findings of the dynamics of heart rate and mood variability. As patients become progressively more ill, variability in heart rate ${ }^{39}$ and $\operatorname{mood}^{40}$ decrease. Thus, healthy individuals, as seen in family medicine, exhibit chaotic/random dynamics whereas ill 


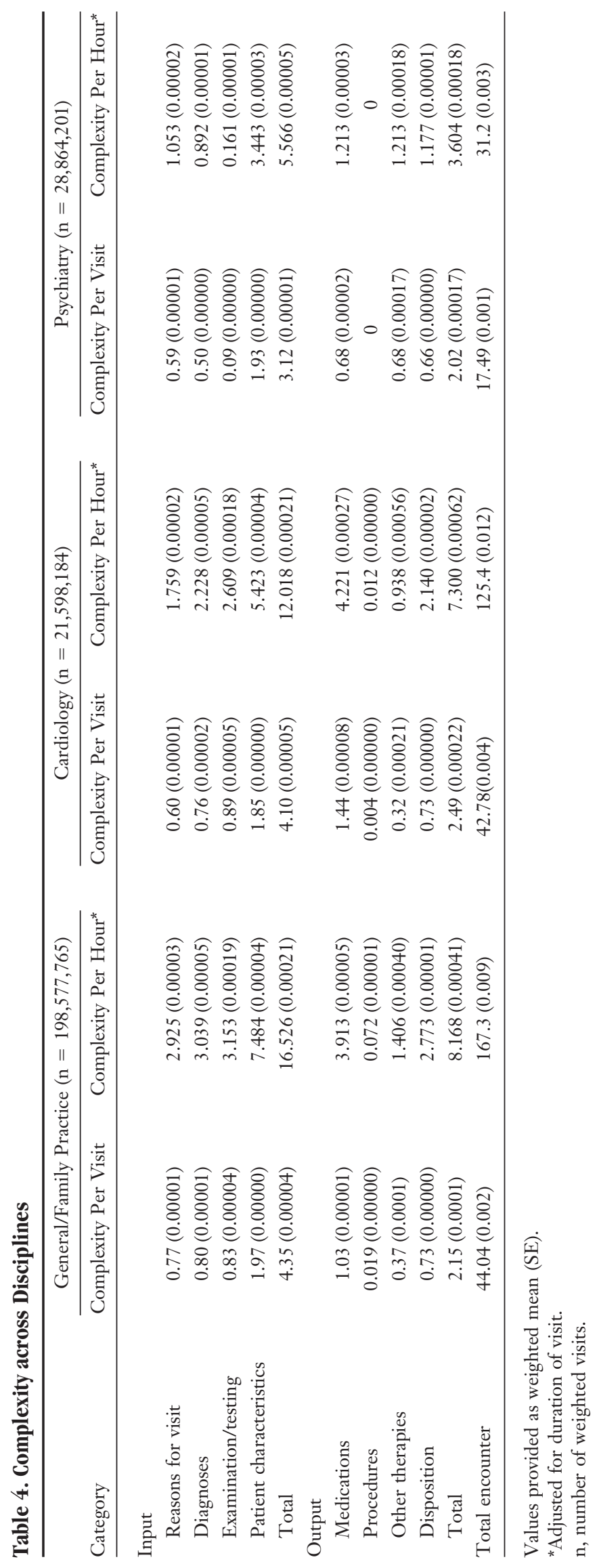


individuals, as seen in cardiology and psychiatry, exhibit periodic dynamics. Thus, family medicine patients should be more variable in their signs and symptoms and less predictable in their response to treatment.

\section{Complexity Rates}

Although the complexity of the encounter was similar between general/family practice and cardiology, complexity is also dependent on the density of the encounters that occur. Inadequate time is often cited as the cause of medical errors. ${ }^{41-43}$ The duration of the visit is dependent on the severity/ complexity of the medical problem ${ }^{9}$ as well as the case mix, the number of tests performed, and whether the patient was previously unknown to the physician. The duration of the visit is associated with the number of medications prescribed, the procedures performed, and the counseling given. ${ }^{44}$ High-volume practitioners deal with this density problem by reducing preventive care and the time spent on building/maintaining the doctor-patient relationship. ${ }^{45}$ Temte et $\mathrm{al}^{46}$ have advocated that an hourly measure of complexity density be used. When adjusted for the duration of visit, general/ family practice was clearly the most complex of the 3 disciplines.

\section{Implications}

The findings that family medicine encounters are more complex may explain the observations that generalists are less likely to provide guideline-concordant care than specialists. That disease-specific mortality rates were inversely related to diseasespecific caseload $^{5,6}$ suggests that disease-specific experience may reduce perceived complexity or that disease-specific delivery systems are in place.

In general, low input complexity with high output complexity would be most desirable. In such a situation, the condition being treated would be clear and understandable and the management options available would permit adaptation to the peculiar circumstances of each patient. Thus, in this study, encounters in cardiology practice were more desirable than those in family medicine from a complexity standpoint.

Because complex systems generate errors in proportion to the level of complexity of the system, ${ }^{31}$ the rate of medical errors would be highest in family medicine. The observation that more than $80 \%$ of errors in family medicine are "systems" errors reflects the complexity of primary care. ${ }^{47}$ If the complexity is high, then errors should attest to the complexity of relationships, the health care system, and knowledge required to provide care. In fact, the complexity of the health care system and poor access to information are major barriers to error reduction. ${ }^{48}$ Studies of medical errors in primary care settings confirm that errors are often because of process problems, ${ }^{41,49,50}$ particularly relationships between the physician and the patient or the health care system. ${ }^{41,42,51,52}$ Preventable errors are attributed to problems with access, documentation, or coordination of care. ${ }^{53}$ In addition, as expected in high-complexity situations, errors are attributed to inadequate knowledge. ${ }^{41,49,54}$ Thus, interspecialty differences may reflect the higher complexity inherent in family medicine. ${ }^{55}$ When comparing care provided by different specialties, adjustment for differences in complexity (as is done with case-mix differences) would provide a clearer picture of interspecialty differences.

If high complexity leads to disproportionately poorer levels of guideline adherence and potentially more medical errors, how can this complexity be reduced? Although the complexity of the individual encounter is similar in general/family practice and cardiology, the density of care provided clearly made general/family practice the more complex of these disciplines. Hence, one approach could be to reduce the density by increasing the time allotted to the encounter. Although financially difficult, this option may be the most attractive to the family physician. Systems that allow for more time with the patient and have multidisciplinary teams in place are more likely to get higher-quality results and may result in better financial return for family physicians. ${ }^{56-58}$

Because complexity of the input is critical to overall complexity, the optimal approach may be to reduce the complexity of the input. Thus, outputoriented approaches, such as formulary limitations or restrictions on procedural privileges and medication prescription, will not be effective in significantly reducing overall complexity and could be counterproductive by limiting adaptability. One way to reduce input complexity could be to promote continuity of care, thereby decreasing the number of new (and unfamiliar) patients seen. Other approaches could be to limit the types of patients seen (eg, excluding maternity patients); limit the number of complaints dealt with during 
each encounter; use physician extenders to see uncomplicated patients, thereby decreasing variability; and develop personal areas of expertise (eg, Certificates of Added Qualifications). Reducing input complexity even a small amount could have a drastic effect on overall complexity.

Unfortunately, the trend toward increased required documentation for accountability may further increase the complexity of primary care encounters. Although routine implementation of practice guidelines may seem to decrease complexity by decreasing variability, if such practices lead to poorer health later, then guidelines will only serve to shift complexity, reducing it now at the expense of increasing it later. In fact, practice guidelines may work best in low-complexity settings in which patients are expected to respond in predictable ways (eg, specialty settings like intensive care units).

The recent policy emphasis on promoting the patient-centered medical home as an advanced form of primary care practice that focuses on the key components of primary care (accessible, comprehensive, coordinate and continuous care) redesigns practice relationships and incorporates health information technology; an alternative payment system may provide an opportunity to decrease complexity density by allowing more time for faceto-face interactions with patients who need it. ${ }^{58,59}$

\section{Limitations}

There are several limitations to this study. First, how representative is the NAMCS database? Previous studies in family medicine found that the mean duration of the visit was 9.01 to 15.9 minutes, ${ }^{37,38,44}$ shorter than the 16.2 minutes reported in the NAMCS database. In fact, Gilchrist et $\mathrm{al}^{60}$ found that, using the NAMCS method and form, family physicians overestimate visit duration by 3.7 minutes. Using a patient $\log$, Beasley et $\mathrm{al}^{61}$ found that family physicians addressed a mean of 3.05 problems per visit, with more than 3 problems addressed in $37 \%$ of the encounters; this is comparable to the findings of Flocke et al. ${ }^{62}$ The mean number of medications prescribed (1.77) is comparable to the mean number of medications on patients' problem lists (1.7). ${ }^{37}$ These findings suggest that, for family medicine, NAMCS may underrepresent input complexity and adjusted complexity.

Secondly, there is a concern about the accuracy of the data reported. Previous studies about the accuracy of clinical notes in family medicine found that only $32 \%$ of the clinical content was recorded. However, there was good agreement when ranking physicians based on the content recorded. ${ }^{63}$ In addition, there is no reason to assume that any discipline is less accurate compared with another. If anything, the data from the densest encounters (family medicine) may be the most incomplete. Thus, the complexity of family medicine encounters may be underestimated. Third, the use of diagnostic classifications among psychiatric patients may falsely simplify the complexity observed. ${ }^{64} \mathrm{Fi}-$ nally, the data collected in the NAMCS study was limited and cannot reflect the true richness of the clinical encounter. In addition, although we examined the variability and diversity of encounters, these measures reflect variability and diversity within each discipline and not within individual practices.

\section{Conclusion}

Poorer guideline-concordant care provided in family medicine relative to cardiology and psychiatry may reflect the increased complexity of the encounters and the less predictive nature of patient dynamics in the relatively diverse patients seen in family medicine. In addition to the use of case mix, estimation of input and output complexity may be another tool for adjustment in comparison studies. Because the approach used here to estimate complexity is amenable to computation with basic clinical data, it could be applied by insurers, practices, and quality improvement advocates to assess complexity of care provided by practices or providers.

\section{References}

1. Stange KC, Ferrer RL. Paradox of primary care. Ann Fam Med 2009;7:293-9.

2. Harrold LR, Field TS, Gurwitz JH. Knowledge, patterns of care, and outcomes of care for generalists and specialists. J Gen Intern Med 1999;14:499-511.

3. Melniker LA, Leo PJ. Comparative knowledge and practice of emergency physicians, cardiologists, and primary care practitioners regarding drug therapy for acute myocardial infarction. Chest 1998;113:297-305.

4. Ayanian JZ, Hauptman PJ, Guadagnoli E, Antman EM, Pashos CL, McNeil BJ. Knowledge and practices of generalist and specialist physicians regarding drug therapy for acute myocardial infarction. N Engl J Med 1994;331:1136-42.

5. Nash IS, Corrato RR, Dlutowski MJ, O'Connor JP, Nash DB. Generalist versus specialist care for acute myocardial infarction. Am J Cardiol 1999;83:650-4. 
6. Casale PN, Jones JL, Wolf FE, Pei Y, Eby LM. Patients treated by cardiologists have a lower inhospital mortality for acute myocardial infarctions. J Am Coll Cardiol 1998;32:885-9.

7. Schreiber TL, Elkhatib A, Grines CL, O’Neill WW. Cardiologist versus internist management of patients with unstable angina. J Am Coll Cardiol 1995;26: 577-82.

8. Go AS, Rao RK, Dauterman KW, Massie BM. Systematic review of the effects of physician specialty on the treatment of coronary disease and heart failure in the United States. Am J Med 2000;108:216-26.

9. Greenwald HP, Peterson ML, Garrison LP, et al. Interspecialty variation in office-based care. Med Care 1984;22:14-29.

10. Philbin EF, Jenkins PL. Differences between patients with heart failure treated by cardiologists, internists, family physicians, and other physicians. Am Heart J 2000;139:491-6.

11. Philbin EF, Weil HFC, Erb TA, Jenkins PL. Cardiology or primary care for heart failure in the community setting. Chest 1999;116:346-54.

12. Tavares LR, Velarde LG, de Miranda VA, Mesquita ET. [Perceptions of heart failure diagnosis and management.] Arq Bras Cardiol 2006;87:167-73.

13. Foody JM, Rathore SS, Wang Y, et al. Physician specialty and mortality among elderly patients hospitalized with heart failure. Am J Med 2005;118: $1120-5$.

14. Indridason OS, Coffman CJ, Oddone EZ. Is specialty care associated with improved survival of patients with congestive heart failure? Am Heart J 203;145:209-13.

15. Thompson C, Ostler K, Peveler RC, Baker N, Kinmonth AL. Dimensional perspective on the recognition of depressive symptoms in primary care. Br J Psychiatry 2001;179:317-23.

16. Rost K, Zhang M, Fortney J, Smith J, Coyne J, Smith GR Jr. Persistently poor outcomes of undetected major depression in primary care. Gen Hosp Psychiatry 1998;20:12-20.

17. Simon GE, Goldberg D, Tiemens BG, Ustun TB. Outcomes of recognized and unrecognized depression in an international primary care study. Gen Hosp Psychiatry 1999;21:97-105.

18. Ryan DH. Misdiagnosis in dementia. Intl J Geriatr Psychiatry 1994;9:141-7.

19. Hoffman RS. Diagnostic errors in the evaluation of behavioral disorders. JAMA 1982;248:964-7.

20. Katon W, Von Korff M, Lin E, et al. Collaborative management to achieve treatment guidelines. JAMA 1995;273:1026-31.

21. Olfson M, Klerman GL. Trends in the prescription of psychotropic medications. Med Care 1993;31:559-64.

22. Simon GE, Von Korff M, Rutter CM, Peterson A. Treatment process and outcomes for managed care patients receiving new antidepressant prescriptions from psychiatrists and primary care physicians. Arch Gen Psychiatry 2001;58:395-401.

23. Rosen AK, Reid R, Broemeling AM, Rakovski CC. Applying a risk-adjustment framework to primary care. Ann Fam Med 2003;1:44-51.

24. Smetana GW, Landon BE, Bindman AB, et al. Comparison of outcomes resulting from generalist versus specialist care for a single discrete medical condition. Arch Intern Med 2007;167:10-20.

25. Lynch DC, Whitley TW. Standardized examination performance and specialty choice. Fam Med 1997; 29:421-3.

26. Stafford RS, Saglam D, Cuasino N, et al. Trends in adult visits to primary care physicians in the United States. Arch Fam Med 1999;8:26-32.

27. Ostbye T, Yarnall KSH, Krause KM, Pollak KI, Gradison M, Michener JL. Is there time for management of patients with chronic diseases in primary care? Ann Fam Med 2005;3:209-14.

28. Grant RW, Pirraglia PA, Meigs JB, Singer DE. Trends in complexity of diabetes care in the United States from 1991 to 2000. Arch Intern Med 2006; 164:1134-9.

29. National Center for Health Statistics. National Ambulatory Medical Care Survey. Hyattsville, MD: US Department of Health and Human Services; 2000.

30. Katerndahl DA, Wood R, Jaen CR. Estimating relative complexity of care in ambulatory settings. Ann Fam Med 2010;8:341-7.

31. Bar-Yam Y. Dynamics of complex systems. Reading, MA: Perseus Books; 1997:716.

32. Sabelli HC. Bios: a study of creation. Hackensack, NJ: World Scientific Publishing Company; 2005.

33. Katerndahl D, Ferrer R, Best R, Wang CP. Dynamic patterns in mood among newly diagnosed patients with major depressive episode or panic disorder and normal controls. Prim Care Companion J Clin Psychiatry 2007;9:183-7.

34. Rosser WW. Approach to diagnosis by primary care clinicians and specialists. J Fam Pract 1996; 42:139-44.

35. Graham R, Bagley B, Kilo CM, Spann SJ, Bogdewic SP. Task Force 1. Report of the task force on patient expectations, core values, reintegration, and the new model of family medicine. Ann Fam Med 2004; 2(Suppl 1):S33-S50.

36. Sox HC. Decision-making. J Fam Pract 1996;42: 155-60.

37. Stange KC, Zyzanski SJ, Jaen CR, et al. Illuminating the black box. J Fam Pract 1998;46:377-89.

38. Rethans JJ, Saebu L. Do general practitioners act consistently in real practice when they meet the same patient twice? BMJ 1997;314:1170-3.

39. Goldberger AL, Bhargava V, West BJ, Mandell AJ. Nonlinear dynamics of the heart beat. Physica 1985; 17D:207-14. 
40. Gottschalk A, Bauer MS, Whybrow PC. Evidence of chaotic mood variation in bipolar disorder. Arch Gen Psychiatry 1995;52:947-59.

41. Ely JW, Levinson W, Elder NC, Mainous AG 3rd, Vinson DC. Perceived causes of family physicians' errors. J Fam Pract 1995;40:337-44.

42. Leclere H, Beaulieu MD, Bordage G, Sindon A, Couillard M. Why are clinical problems difficult? Can Med Assoc J 1990;143:1305-11.

43. Croskerry P, Shapiro M, Campbell S, et al. Profiles in patient safety. Acad Emerg Med 2004;11:289-99.

44. Blumenthal D, Causino N, Chang YC, et al. Duration of ambulatory visits to physicians. J Fam Pract 1999;48:264-71.

45. Zyzanski SJ, Stange KC, Langa D, Flocke SA. Trade-offs in high volume primary care practice. J Fam Pract 1998;46:397-402.

46. Temte J, Grasmick M, Barr J, Kunstman J, Jaeger A, Beasley J. Encounter problem density in primary care: a better measure of complexity? Paper presented at: Annual Meeting of the North American Primary Care Research Group; October 20-23, 2007; Vancouver, British Columbia.

47. Rivo ML. Can we avoid errors in family practice? Fam Pract Mgmt 2002;9:15-6.

48. Leape LL. Systems analysis approach to medical error. J Eval Clin Pract 1997;3:213-22.

49. Makeham MAB, Dovey SM, County M, Kidd MR. International taxonomy for errors in general practice. Med J Austral 2002;177:68-72.

50. Elder NC, Vonder Meulen MB, Cassedy A. Identification of medical errors by family physicians during outpatient visits. Ann Fam Med 2004;2:125-9.

51. Bhasale AL, Miller GC, Reid SE, Britt HC. Analysing potential harm in Australian general practice. Med J Austral 1998;169:73-6.

52. Singh H, Graber M. Reducing diagnostic error through medical home-based primary care reform. JAMA 2010;304:463-4.
53. Britt H, Miller GC, Steven IO, et al. Collecting data on potentially harmful events. Fam Pract 1997;14: 101-6.

54. Timpka T, Ekstrom M, Bjurulf P. Information needs and information seeking behavior in primary health care. Scand J Prim Health Care 1989;7:105-9.

55. Van Weel C. The uses of error: the complexity of general practice. Lancet 2001;357:462.

56. Rosser WW, Colwill JM, Kasperski J, Wilson L. Patient-centered medical homes in Ontario. N Engl J Med 2010;362:e7.

57. Reid RJ, Fishman PA, Yu O, et al. Patient-centered medical home demonstration: a prospective, quasiexperimental, before and after evaluation. Am J Manag Care 2009; 15:e71-e87 (1-3).

58. Reid RJ, Coleman K, Johnson EA, et al. The group health medical home at year two: cost savings, higher patient satisfaction, and less burnout for providers. Health Aff (Millwood) 2010;29:835-43.

59. Stange KC, Nutting PA, Miller WL, et al. Defining and measuring the patient-centered medical home. J Gen Intern Med 2010;25:601-12.

60. Gilchrist VJ, Stange KC, Flocke SA, McCord G, Bourguet CC. Comparison of the National Ambulatory Medical Care Survey (NAMCS) measurement approach with direct observation of outpatient visits. Med Care 2004;42:276-80.

61. Beasley JW, Hankey TH, Erickson R, et al. How many problems do family physicians manage at each encounter? A WREN Study. Ann Fam Med 2004;2: 405-10.

62. Flocke SA, Frank SH, Wenger DA. Addressing multiple problems in the family medicine office visit. J Fam Pract 2001;50:211-6.

63. Rethans JJ, Martin E, Metsemakers J. To what extent do clinical notes by general practitioners reflect actual medical performance? A study using simulated patients. Br J Gen Pract 1994;44:153-6.

64. Boisot M, Child J. Organizations as adaptive systems in complex environments. Organ Sci 1999;10:237-52. 